\title{
Mutualistic Fungal Endophyte Colletotrichum tofieldiae Ct0861 Colonizes and Increases Growth and Yield of Maize and Tomato Plants
}

\author{
Sandra Díaz-González ${ }^{1,2,3}{ }^{10}$, Patricia Marín ${ }^{1}$, Roberto Sánchez ${ }^{1}$, Cristina Arribas ${ }^{1}$, \\ John Kruse ${ }^{1}$, Pablo González-Melendi ${ }^{2,3} \mathbb{D}$, Frédéric Brunner ${ }^{1, *}$ and Soledad Sacristán $2,3, * \mathbb{D}$ \\ 1 PlantResponse Biotech, S.L. Centro de Empresas, Campus de Montegancedo, 28223 Pozuelo de Alarcón, \\ Madrid, Spain; sandra.diaz@plantresponse.com (S.D.-G.); patricia.marin@plantresponse.com (P.M.); \\ roberto.sanchez@plantresponse.com (R.S.); cristina.arribas@plantresponse.com (C.A.); \\ john.kruse@plantresponse.com (J.K.) \\ 2 Centro de Biotecnología y Genómica de Plantas (CBGP), Universidad Politécnica de \\ Madrid (UPM) - Instituto Nacional de Investigación y Tecnología Agraria y Alimentaria (INIA) Campus \\ Montegancedo UPM, 28223 Pozuelo de Alarcón, Madrid, Spain; pablo.melendi@upm.es \\ 3 Departamento de Biotecnología-Biología Vegetal, Escuela Técnica Superior de Ingeniería Agronómica, \\ Alimentaria y de Biosistemas, Universidad Politécnica de Madrid (UPM), 28040 Madrid, Spain \\ * Correspondence: frederic.brunner@plantresponse.com (F.B.); soledad.sacristan@upm.es (S.S.)
}

Received: 20 August 2020; Accepted: 26 September 2020; Published: 1 October 2020

\begin{abstract}
Facing rising global food demand in a sustainable way is a great challenge of modern agriculture. Thus, the increase of crop productivity and resilience in an adverse climate scenario is urgently needed. Fungal endophytes have been described as potential biological tools to improve plant yield and tolerance to biotic and abiotic stresses; however, their application in agriculture needs further research. The fungal endophyte Colletotrichum tofieldiae strain Ct0861 establishes a mutualistic interaction with Arabidopsis thaliana, promoting plant growth and silique production at low phosphate conditions. Until now, its ability to colonize and confer benefits to other plant species remained unexplored. Here, we show that Ct0861 colonizes and promotes growth in vitro of maize (Zea mays L.) and tomato (Solanum lycopersicum L.) seedlings, resulting in significantly larger shoot length and weight. Greenhouse and field experiments in optimal nutritional conditions showed an increase between $12 \%$ and $22 \%$ of yield in both tomato and maize. The inoculated plants were not suffering from phosphate starvation, which points at different modes of action not elucidated yet. These results indicate that the beneficial effect of Ct0861 may extend to other plant species of economic importance, making Ct0861 a potentially valuable inoculant.
\end{abstract}

Keywords: Colletotrichum tofieldiae; fungal endophyte; Zea mays L.; Solanum lycopersicum L.; yield increase; plant growth promoter; sustainable agriculture; biostimulant

\section{Introduction}

Feeding the growing global population in an economically and environmentally sustainable way is the main challenge of agriculture in the 21st century. Crop intensification usually relies on unsustainable agricultural practices with increasing agrochemical inputs, generating significant ecological problems [1-3]. Therefore, there is an urgent need to develop novel technologies that provide acceptable and durable solutions to increase plant productivity under variable climate conditions, along with the reduction of the incidence of plant diseases and pests [2,4,5]. Although the current agricultural market offers a wide list of microbial-based commercial products [6], their application as supplements to overcome crop threats is not widespread in conventional agriculture [7]. This is mainly 
due to variable performance in the field and their limited host range [8]. Thus, further studies and a better understanding of plant-microbe interactions in arable and horticultural crop species under field conditions are required to settle microbial products as common agricultural inputs [9-11].

Plants in natural ecosystems establish interactions with fungal endophytes, a highly diverse group of fungi that naturally colonize internal plant tissues without causing disease symptoms for at least part of their life cycle [12-15]. Many of these interactions seem to be mutualistic, with exchange of benefits between the host and the endophyte. The endophyte can promote plant growth, facilitate plant adaptation, and increase tolerance to biotic and abiotic stresses, while the host plant provides shelter and nutrients to the fungus $[13,16-18]$. Although studies on plant-fungal endophyte interactions have frequently been carried out under controlled laboratory conditions, these microorganisms have a real potential to be used in agricultural systems for improvement of plant health, yield, and adaptation to stress and limiting conditions [7].

Colletotrichum tofieldiae strain Ct0861 (Ct0861) has been characterized as a fungal endophyte in natural populations of Arabidopsis thaliana in Central Spain [19,20]. It was demonstrated that the fungus establishes a mutualistic interaction with $A$. thaliana, promoting plant growth and fertility by the translocation of phosphate $(\mathrm{Pi})$ to the host under Pi starvation conditions [20,21]. Thus, the Ct0861- $A$. thaliana interaction has been embraced as a novel model to analyze endophytic fungi-plant associations in non-mycorrhizal plants, such as A. thaliana and other Brassicaceae. Furthermore, C. tofieldiae is a worldwide distributed species that has been isolated from many different wild plants, including both monocots and dicots, growing in diverse ecosystems [22-25]. These characteristics suggest a possible extension of its beneficial effect to other hosts and, therefore, its application to commercial crops. However, the potential benefit of this endophytic fungus in plant species of agricultural interest had not been explored yet.

Maize (Zea mays L.) and tomato (Solanum lycopersicum L.) are among the most important crops in the world. Maize is one of the most cultivated arable crops, with a global production that reached 1134 million tons in 2017, covering 197 million hectares [26]. This production greatly contributes to global food security, since it plays a key role in both human and livestock nutrition worldwide. Tomato is the second most important vegetable crop after potato [26]. Spain is among the ten leading tomato producers in the world, and the second in the European Union (EU) with a total production of five million tons in 2017 [26,27]. Tomato production is among the most advanced and innovative horticultural industries; nonetheless, improvements in the production systems are expected to continue in order to increase sustainability, for instance, by the implementation of microorganisms that might allow the reduction of chemical inputs. Although a great diversity of studies have demonstrated the beneficial impact of certain microorganisms on plant development and yield, such as arbuscular mycorrhizal fungi (AMF) and plant growth promoting (PGP) bacteria, studies on the interaction of maize and tomato with endophytic fungi are still scarce [9]. The aim of the present work was thus to test the ability of $\mathrm{Ct} 0861$ to colonize both a monocot and a dicot crop and to stimulate plant development and yield under agricultural conditions. For this, Ct0861 has been assayed in maize and tomato under different growing conditions, using in vitro experiments and open field and greenhouse trials.

\section{Materials and Methods}

\subsection{Fungal Inoculum}

The fungus Colletotrichum tofieldiae strain Ct0861 was originally isolated in the central Iberian Peninsula [19], and it is deposited at the Spanish Type Culture Collection (CECT) with accession number CECT 20833. To obtain the fungal inoculum, conidia were harvested with sterile water from seven-days-old cultures on potato-dextrose-agar (PDA) as described in Hiruma et al. [20]. 


\subsection{In vitro Experiments}

Maize seeds (Zea mays L. variety LG 34.90) were sterilized following the protocol described in Roca et al. [28] with minor adaptations ( $3 \mathrm{~min}$ in distilled water, $10 \mathrm{~min}$ in 70\% ethanol, and $15 \mathrm{~min}$ in $20 \%$ bleach, followed by 3 washes of 3 min each in sterile distilled water), and then inoculated at a dose of $10^{3}$ conidia.seed $^{-1}$, or sterile distillated water for the negative controls. This dose was derived from

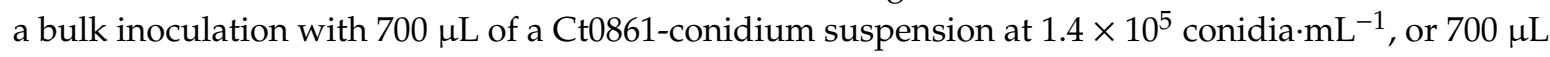
water for negative controls, applied to sets of 100 seeds in 50-mL falcon tubes that were then shaken vigorously to obtain an even distribution on the seed surface. Seeds were placed in squared petri plates with $1 / 2 \mathrm{MS}$ agar medium at pH 5.7 and incubated in darkness at $24^{\circ} \mathrm{C}$.

Tomato seeds (Solanum lycopersicum L. variety Kenety F1) were sterilized ( $5 \mathrm{~min}$ in $70 \%$ ethanol $-0.05 \%$ Sodium Dodecyl Sulfate and $5 \mathrm{~min}$ in absolute ethanol) and inoculated at a dose of $10^{4}$ conidia.seed ${ }^{-1}$ or sterile distillated water for the negative controls. This dose was derived from a bulk inoculation with $160 \mu \mathrm{L}$ of a Ct0861-conidium suspension at $3.8 \times 10^{6}$ conidia $\cdot \mathrm{mL}^{-1}$, or $160 \mu \mathrm{L}$ water for negative controls, applied to sets of 60 seeds in $15-\mathrm{mL}$ falcon tubes that were then shaken to allow an even distribution of the conidia on the seed surface. Square petri plates were filled with $70 \mathrm{~mL}$ of $1 / 2 \mathrm{MS}$ agar medium at $\mathrm{pH}$ 5.7. Afterwards, the agar at $6 \mathrm{~cm}$ under the upper edge was sliced and removed, in order to avoid the shoots being in direct contact with the growth medium. Treated seeds were sown on the ledge of the agar and the plates were set vertically in a growth chamber at $24{ }^{\circ} \mathrm{C}$ with a long-day photoperiod ( $14 \mathrm{~h}$ light/10 h dark).

Shoot and root length and fresh weight of both maize and tomato seedlings were evaluated after seven days of incubation. Two independent in vitro experiments with five replicates and five plants per replicate and per treatment were carried out for each plant species. The data of a total of 50 plants per treatment were pooled for statistical analyses.

Ct0861 colonization of the seedlings was evaluated by fungal re-isolation from surface-sterilized plant tissues at 10 days after sowing. Roots, mesocotyls, and apical tissues of coleoptile of 15 maize seedlings and roots, and hypocotyls and cotyledons of 15 tomato seedlings were cut into small pieces and surface sterilized by adapting the protocol described in García et al. [19] (1 $\mathrm{min}$ in distilled water, $3 \mathrm{~min}$ in 20\% bleach, and 3 times of $1 \mathrm{~min}$ in sterile distilled water). Tissue pieces were incubated for one week in moist chamber and PDA plates, and observed under the binocular (Supplementary Figure S1).

\subsection{Confocal Microscopy}

Maize and tomato seeds were grown and inoculated as described for the in vitro experiments, but using a transgenic Ct0861 strain that expresses cytoplasmic GFP (Ct0861-GFP) [20]. The plant material samples were observed on a Zeiss 880 confocal microscope under the excitation of the laser line $405 \mathrm{~nm}$ to detect the cell wall autofluorescence and the emission was collected in the range 410-585 nm. GFP signal was excited by the argon laser line of $488 \mathrm{~nm}$ and the emission was detected in the range 493-598 nm. To rule out any crosstalk, both channels were acquired sequentially. The figure was composited on Adobe Photoshop CS3 extended. To enhance the contrast of the images, only the automatic levels tool was applied.

\subsection{Maize Field Trial}

\subsubsection{Site Description, Irrigation, and Fertilization}

The experiment was conducted from May to October 2018 in an experimental station located at Pilar de la Horadada, Alicante ( $37^{\circ} 51^{\prime} 46.0^{\prime \prime} \mathrm{N}-0^{\circ} 48^{\prime} 30.6^{\prime \prime} \mathrm{W}, 35 \mathrm{~m}$ above mean sea level) in the south-eastern part of the Iberian Peninsula. According to the Köppen-Geiger classification, the climate is hot steppe (BSh) [29] with average annual temperature of $17.6^{\circ} \mathrm{C}$ (ranging from $10.8^{\circ} \mathrm{C}$ in January to $25.5^{\circ} \mathrm{C}$ in August). Mean annual precipitation is $313 \mathrm{~mm}$, with June, July, and August being especially dry months (average of 7, 2, and $7 \mathrm{~mm}$, respectively) [30]. The mean annual humidity is $71 \%$ [30]. 
Field soil physico-chemical properties were analyzed before maize sowing and after harvesting (Supplementary Table S1). Based on the results, the experimental field was amended with nitrogen $\left(176 \mathrm{~kg} \cdot \mathrm{ha}^{-1}\right)$ and sulphur $\left(96 \mathrm{~kg} \cdot \mathrm{ha}^{-1}\right)$ fertilizers as recommended for maize. Plants were watered by drip irrigation and water requirements were calculated using long-term data from the closest climate station, located in San Javier ( $37^{\circ} 47^{\prime} 20^{\prime \prime} \mathrm{N}, 0^{\circ} 48^{\prime} 12^{\prime \prime}$ W) [31].

\subsubsection{Plant Material and Inoculation}

Three different doses of Ct0861 $\left(2 \times 10^{2}, 2 \times 10^{3}, 2 \times 10^{4}\right.$ conidia seed $^{-1}$ for CtST1-Zm, CtST2-Zm and CtST3-Zm, respectively, Table 1), and water as negative control (M-Zm), were applied on fungicide-free maize seeds (Zea mays L. variety LG 34.90) just prior to sowing. These doses were derived from a bulk inoculation with $3 \mathrm{~mL}$ of Ct0861-conidium suspensions at $3 \times 10^{4}, 3 \times 10^{5}$, and $3 \times 10^{6}$ conidia. $\mathrm{mL}^{-1}$; or $3 \mathrm{~mL}$ water for the negative control $(\mathrm{M}-\mathrm{Zm})$, applied to sets of $100 \mathrm{~g}$ of seeds (approx. 430 seeds) in clean plastic bags that were then shaken vigorously to obtain an even distribution of the conidia on the seed surface.

Table 1. Experimental design for the open-field maize trial.

\begin{tabular}{ccc}
\hline Treatment Name $^{\mathbf{1}}$ & Dose (Conidia·Seed $^{\mathbf{- 1}} \mathbf{~}^{\mathbf{2}}$ & Dose (Conidia.ha $^{\mathbf{- 1}}$ ) \\
\hline M-Zm & - & - \\
CtST1-Zm & $2 \times 10^{2}$ & $2 \times 10^{7}$ \\
CtST2-Zm & $2 \times 10^{3}$ & $2 \times 10^{8}$ \\
CtST3-Zm & $2 \times 10^{4}$ & $2 \times 10^{9}$ \\
\hline 1. Each maize treatment comprises 4 replicates (plots). ${ }^{2}$ Seeds were treated prior sowing with a conidium suspension \\
in water at the indicated doses or water for the negative control (M-Zm).
\end{tabular}

\subsubsection{Trial Design}

Four treatments with four replicates (plots) each were included in the maize experiment (Table 1). The total parcel area was $1182 \mathrm{~m}^{2}$ with 21 rows of $52.5 \mathrm{~m}$ in length and $0.75 \mathrm{~m}$ distance between rows. Each plot consisted in three rows of $9 \mathrm{~m}$ in length, and a total area of $20.25 \mathrm{~m}^{2}$. Due to the colonization potential of control plants by Ct0861 through soil dissemination, plots containing control treatments were separated from the Ct0861-inoculated plots by a distance of $6 \mathrm{~m}$, following a split-plot design. Border and buffer plants were grown all along the plots and in the separation areas between control and inoculated plants.

\subsubsection{Measurements}

All measurements were taken from the plants growing in the middle row of each plot. Plant stem height was recorded from 20 plants per plot (80 plants per treatment) at reproductive stage R3. The number of mature cobs per plant was recorded for 4 plants per plot (16 plants per treatment). To calculate mean cob weight per plant, mature cobs from 44 plants from the same plot were collected and weighted together. Then, they were de-kernelled and kernels were weighted together to determine mean plant yield for each plot. The weight of 1000 of those kernels was determined twice for each plot. Kernel humidity was assessed in order to normalize weights to $15.5 \%$ of water content. Yield in t.ha ${ }^{-1}$ was calculated according to trial plant density $\left(75,000\right.$ plants $\left.^{\prime} \mathrm{ha}^{-1}\right)$.

\subsection{Tomato Greenhouse Trial}

\subsubsection{Site Description, Irrigation, and Fertilization}

The experiment was conducted from February to September 2019 in a production greenhouse located at the experimental station already described for the maize field trial in 2.4.1. Tomato plantlets were grown in peat (Projar, Sustrato Seed Pro5050) for two months, then transferred to the greenhouse and transplanted to $8 \mathrm{~L}$ pots filled with the substrate mixture $50 \%$ peat (Projar, Sustrato 
Seed Pro 5050)—50\% perlite (Projar, Perlita Expandida 3-6 mm). Supplementary Table S2 shows the physico-chemical properties of these two substrates. Plants were watered with a drip irrigation system as needed, based on commonly-applied irrigation practices for the region, and followed a standard fertigation program for tomato (Supplementary Table S3).

\subsubsection{Plant Material and Inoculation}

Tomato seeds free of fungicide (Solanum lycopersicum L. variety Kenety F1) were inoculated at a dose of $10^{5}$ conidia.seed $^{-1}$ for the seed treatment (CtST-Sl, Table 2). This dose was derived from a bulk inoculation with $400 \mu \mathrm{L}$ of $\mathrm{Ct} 0861$-conidium suspension at $5 \times 10^{7}$ conidia. $\mathrm{mL}^{-1}$ applied to sets of 170 seeds in 50-mL falcon tubes that were then shaken to allow a proper distribution of the conidia on the seed surface. Water was applied on seeds as negative control (M-Sl). In the irrigation treatment (CtIR-Sl, Table 2), tomato plants were treated ten days after transplanting by adding $10 \mathrm{~mL}$ of Ct0861 conidium suspension at $2 \times 10^{5}$ conidia $\cdot \mathrm{mL}^{-1}$ on the substrate to reach a dose of $2 \times 10^{6}$ conidia. $_{\text {plant }}{ }^{-1}$. At the same time, CtST-Sl and M-Sl plants received a control application of $10 \mathrm{~mL}$ water.

Table 2. Experimental design for the greenhouse tomato trial.

\begin{tabular}{cccc}
\hline Treatment Name $^{\mathbf{1}}$ & Dose (Conidia.Seed $^{\mathbf{1}}$ or Plant $^{-1}$ ) & Dose (Conidia.ha $^{-1}$ ) & Application $^{\mathbf{2}}$ \\
\hline M-Sl & - & - & \\
CtST-Sl & $10^{5}$ & $10^{9}$ & Seed treatment \\
CtIR-Sl & $2 \times 10^{6}$ & $2 \times 10^{10}$ & Irrigation \\
\hline
\end{tabular}

1. Each tomato treatment comprised 6 replicates of 8 plants each. ${ }^{2}$. Seeds were treated prior sowing with a conidium suspension in water at the indicated doses (CtST-Sl treatment), or water for the negative control (M-Sl) and CtIR-Sl treatments. The irrigation treatment consisted of watering the plants ten days after transplanting with $10 \mathrm{~mL}$ of a conidium suspension (CtIR-Sl treatment), or water for M-Sl and CtST-Sl treatments.

\subsubsection{Trial Design}

A randomized complete block (RCB) design was used in the tomato experiment with three treatments (Table 2), each with six replicates of eight plants. The total greenhouse area was $56 \mathrm{~m}^{2}$ with 8 rows of $7 \mathrm{~m}$ and $1 \mathrm{~m}$ distance between rows. Border and buffer plants were planted around the trial plot.

\subsubsection{Measurements}

In total, five harvests were carried out until the end of the crop cycle (08/07/2019, 05/08/2019, 09/08/2019, 16/08/2019, and 30/08/2019). Mature fruits were collected, counted, and weighted individually. The total harvest period was divided into three regular time intervals: (a) 08-25/07/2019, (b) 26/07-12/08/2019, (c) 13-31/08/2019. Harvest parameters belonging to the same time interval were summed and differences among intervals were analyzed. The final total weight was calculated by the sum of the five harvests. Mature fruits were collected, counted, and weighted individually. Yield per hectare was calculated based on a density of 20,000 plants.ha ${ }^{-1}$. To evaluate root weight, four plants per block were randomly selected at the end of the crop cycle. Roots were washed with tap water and dried at room temperature until no change in weight was observed.

\subsection{Detection of Fungal Colonization}

Ct0861 colonization of tomato plants was evaluated by re-isolation (as described in the in vitro experiments) in roots, stems, and leaves; and molecular detection of Ct0861 by real-time PCR in roots of 20 plants per treatment one month after inoculation. For real-time PCR, DNA was extracted from root tissues using DNeasy Plant Mini Kit (Qiagen) and its integrity verified by agarose gel electrophoresis. Brilliant III Ultra-Fast QPCR Master Mix (Agilent) was used for the PCR reaction as reagent mixture in combination with the $C$. tofieldiae specific primers PRB110_00602\#3 5' CTCGTGTGACTGCGTTGTTG $3^{\prime}$ and 5'TGGGTTGTGCGGGATTCAG 3'; and dual labelled probe DLP PRB110_00602\#3 (5'-6-FAM- 
ATAGGTTTCCTACGCTGGCGCGTT-TAMRA-3'), using $20 \mathrm{ng}$ of total template DNA in $10 \mu \mathrm{L}$ of total reaction volume. Amplification reactions were carried out using the LightCycler ${ }^{\circledR} 480$ System (Roche), including four technical replicates for each sample. Data acquisition and analysis were performed using the LightCycler ${ }^{\circledR} 480$ SW 1.5 software. Ct0861 colonization of maize plants was assessed by real-time PCR in the roots from one plant per plot at harvest by using the same real-time PCR protocol as for the tomato plants.

\subsection{Statistical Analyses}

Statistical analyses were performed in RStudio software (Version 1.0.143). In order to check normality and homogeneity of variances assumptions, both Shapiro-Wilk normality test and Bartlett test of homogeneity of variance were performed using 'shapiro.test' and 'bartlett.test' functions, respectively ( $\mathrm{R}$ package stats). Two-sample t-tests $(p<0.05)$ were used to check for inoculation effects, using the R package stats. For two-sample comparisons of data that did not meet the normality assumption, data were first checked for homogeneity of variances with the Fligner-Killeen test by running 'fligner.test' function ( $\mathrm{R}$ package stats) and then a two-sample Wilcoxon-Mann-Whitney (WMW) Test $(p<0.05)$ was conducted using the "wilcox_test" function (R package coin). Multiple comparisons of data meeting normality and homogeneity of variances were performed by ANOVA tests $(p<0.05)$ using 'aov' function (R package stats). Multiple comparisons of means were analyzed by least significant difference test (LSD test) using 'LSD.test' function (R package agricolae). Kruskal-Wallis $(\mathrm{KW})$ rank sum test $(p<0.05)$ was undertaken for data that did not meet ANOVA assumptions by using 'kruskal.test' function (R package stats). Post-hoc Nemenyi pairwise test for multiple comparisons of mean rank sums was conducted in this case using 'posthoc.kruskal.nemenyi.test' function ( $R$ package PMCMR). To analyze the effect of factors "treatment", "harvest interval", and their interaction on tomato yield parameters, a two-factor analysis of variance of aligned rank transformed data was conducted, since data did not meet normality assumptions. For this, data were first transformed with 'art' function (R package ARTool). The appropriateness of the procedure was verified by checking that the column sums of aligned responses and the $\mathrm{F}$ values of ANOVAs on aligned response not of interests tended to zero with 'summary' function ( $R$ package base). Finally, ANOVA was run on transformed data using 'anova' function ( $R$ package stats) with table type analysis of deviance table (Type III Wald F tests with Kenward-Roger degrees of freedom) and a mixed effects model ('Imer'). Random effects were accounted for replicate (or plot) in all statistical analysis.

\section{Results}

\subsection{Ct0861 Colonizes Maize and Tomato Plants and Increases Maize and Tomato Seedlings Growth In Vitro}

Maize and tomato seeds were inoculated with Ct0861 spores and grown in vitro on MS-agar plates to evaluate the impact of the fungus on the growth of the plants at early phenological stages. After seven days, both maize and tomato seedlings inoculated with Ct0861 presented significantly longer shoots (WMW test, tomato: $Z=0.0057, p=0.002$; maize: $Z=2.7315, p=0.005$ ) with higher fresh weight (WMW test, tomato: $Z=3.5369, p<0.001$; maize: $Z=2.4239, p=0.02$ ) in comparison to the untreated controls (Figure 1, Table 3). In terms of root development, Ct0861-both inoculated maize and tomato seedlings tended to result in longer roots with greater fresh weight than the non-treated plants (Figure 1), although a significant increase was only observed in the case of tomato root length (WMW test, $\mathrm{Z}=3.3155, p=0.002$; Table 3). 


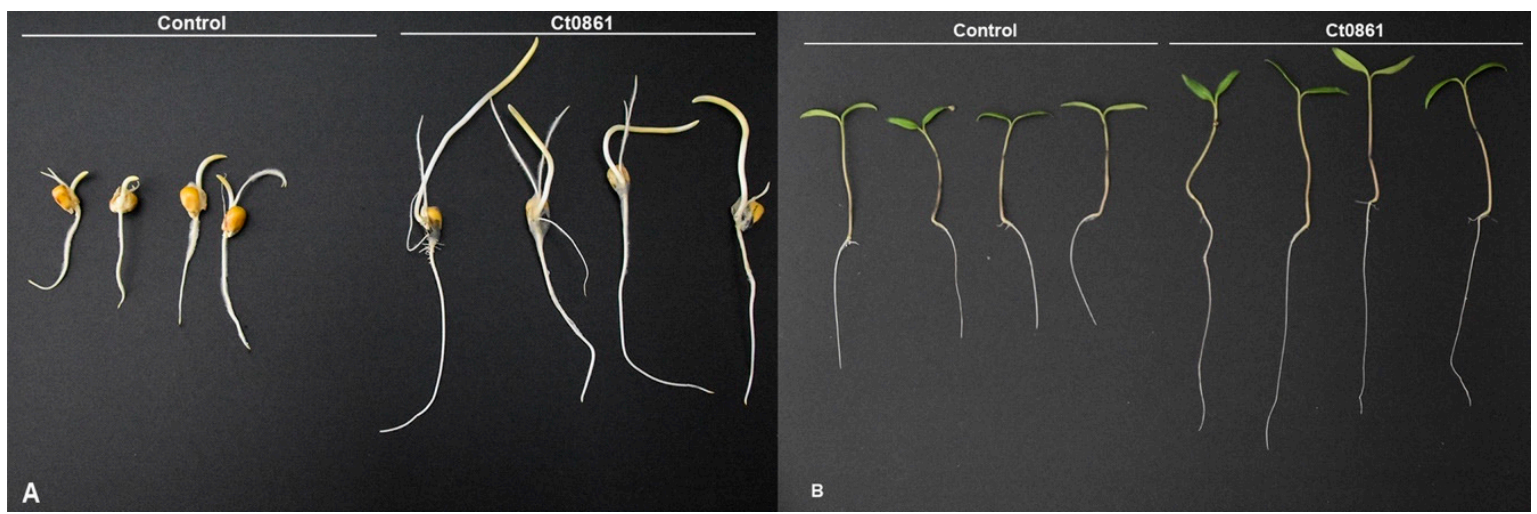

Figure 1. Representative image of maize (A) and tomato (B) seedlings from seeds inoculated with Ct0861 or water for control and grown in $\frac{1}{2}$ MS medium for six days. Maize seeds were inoculated at a dose of $10^{3}$ conidia.seed ${ }^{-1}$ and grown in darkness at $24^{\circ} \mathrm{C}$. Tomato seeds were inoculated at a dose of $10^{4}$ conidia.seed ${ }^{-1}$ and cultivated vertically at $24^{\circ} \mathrm{C}$ with a photoperiod of $14 \mathrm{~h}$ of light and $10 \mathrm{~h}$ of darkness.

The colonization of the plants by Ct0861 was validated by the re-isolation of the fungus from the different tissues of the plants at 10 days after seed inoculation. No external signs of Ct0861 were observed in living tissues, but it was possible to observe the typical conidiomata called acervuli in cut off plant tissue sections that were surface sterilized and incubated in moist chamber (Supplementary Figure S1). We observed acervuli in surface-sterilized tissues of $93 \%$ of tomato and $100 \%$ of maize seedlings. In tomato, acervuli were observed in sections of roots and hypocotyl of $86 \%$ of the seedlings and in sections of cotyledons of $93 \%$ of the seedlings. In the case of maize, acervuli were observed in sections from both root and the coleoptile in all seedlings. No Ct0861 growth was observed in tissues from non-inoculated plants. The fact that the sections had been surface-sterilized suggests that Ct0861 was able to colonize the inner part of the different tissues of the germinating seedling, as described similarly in Hiruma et al. [20].

Table 3. Effect of Ct0861 on root and shoot growth of maize and tomato seedlings grown in vitro from inoculated seeds.

\begin{tabular}{ccccc}
\hline Treatments & Root Length $\mathbf{( c m )}$ & Root Weight $(\mathbf{m g})$ & Shoot Length $\mathbf{( c m )}$ & Shoot Weight $(\mathbf{m g})$ \\
\hline Maize & & & & \\
\hline Control & $9.5 \pm 5.3 \mathrm{a}$ & $190.3 \pm 121.5 \mathrm{a}$ & $10.3 \pm 5.3 \mathrm{a}$ & $175.7 \pm 122.0 \mathrm{a}$ \\
Ct0861 & $10.5 \pm 4.0 \mathrm{a}$ & $198.1 \pm 118.2 \mathrm{a}$ & $16.1 \pm 6.2 \mathrm{~b}$ & $246.5 \pm 141.1 \mathrm{~b}$ \\
Tomato & & & & \\
Control & $5.7 \pm 2.2 \mathrm{a}$ & $8.0 \pm 2.1 \mathrm{a}$ & $3.3 \pm 1.3 \mathrm{a}$ & $28.5 \pm 14.5 \mathrm{a}$ \\
Ct0861 & $7.3 \pm 2.1 \mathrm{~b}$ & $8.2 \pm 2.4 \mathrm{a}$ & $4.2 \pm 1.1 \mathrm{~b}$ & $40.7 \pm 14.5 \mathrm{~b}$ \\
\hline
\end{tabular}

Data are means \pm standard deviations of $n=50$ plants for each host and were analyzed by two sample Wilcoxon-Mann-Whitney test. Different letters within each column and plant species indicate significant differences among treatments $(p<0.05)$.

We used live cell confocal microscopy with the transgenic Ct0861 strain expressing GFP (Ct0861-GFP) originally described by Hiruma et al. [20] to observe in more detail the colonization process of maize and tomato seedlings six days after seed inoculation. We observed fungal hyphae growing inside the roots of both maize and tomato (Figure 2, Supplementary Videos S1 and S2). In maize, we could see hyphae occupying the intercellular space and directly penetrating epidermal root cells (Figure 2A,B and Supplementary Video S1). In tomato, a highly-dense net of hyphae was observed around the root, with some hyphae occupying the inside of epidermal cells and ramifying towards adjacent cells (Figure 2C,D, Supplementary Video S2). We did not observe hyphae inside the mesocotyl or coleoptile of maize; and neither inside the hypocotyl or cotyledons of tomato 
seedlings. Instead, we observed hyphae growing on the surface that produced melanized appressoria but did not differentiate invasive hyphae inside the plant tissue, similarly to what was described in Hiruma et al. [20] (data not shown). These results suggest that colonization of upper parts of the plant is carried out from the root and not directly from appressoria.
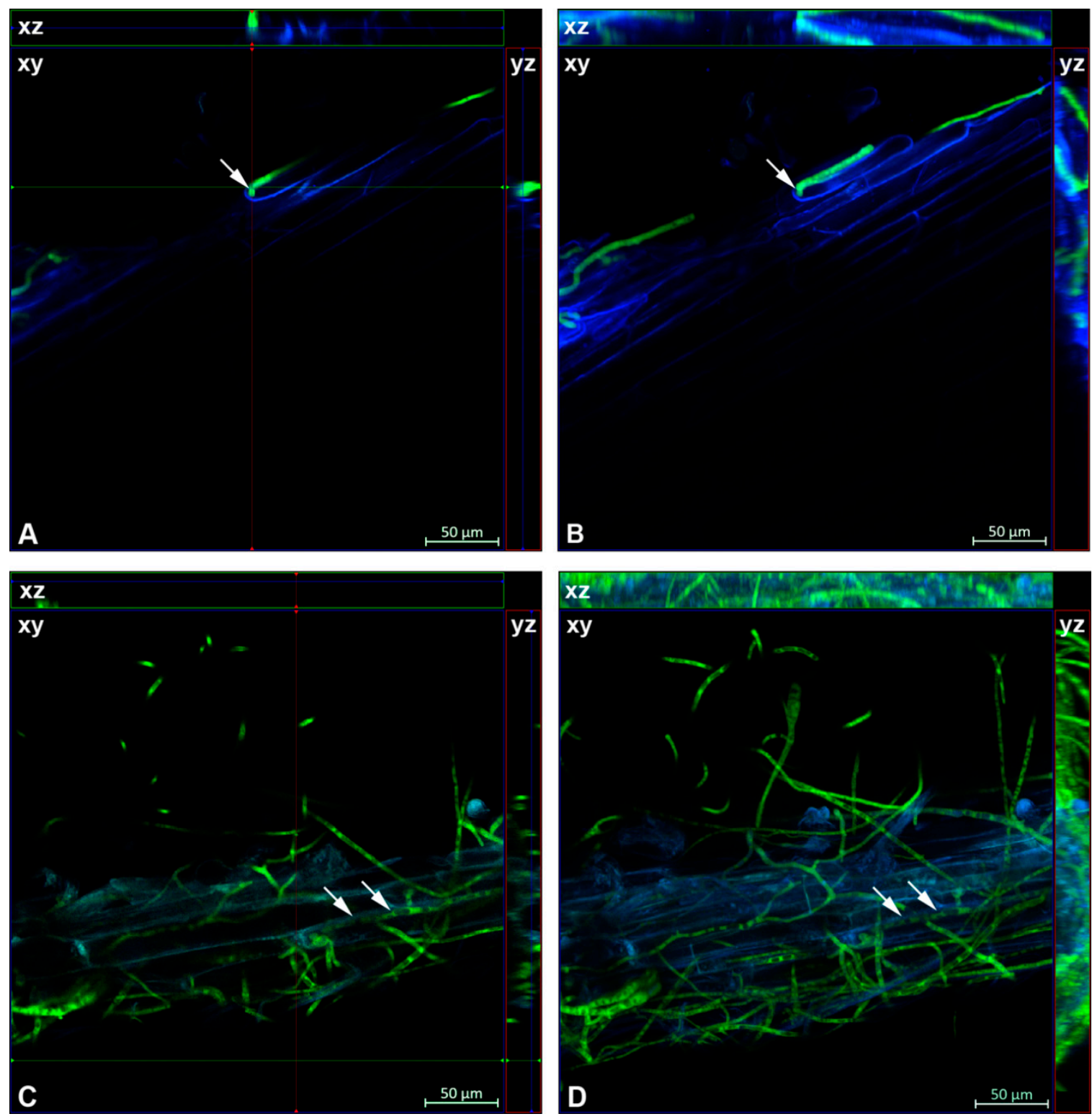

Figure 2. Orthogonal projections obtained on a Zeiss 880 confocal microscope. (A,B) Maize roots inoculated with Ct0861-GFP. (C,D) Tomato roots inoculated with Ct0861-GFP. (A) Projection at position $\mathrm{z}=13$. (B) Maximum projection. (C) Projection at position $\mathrm{z}=7$. (D) Maximum projection. Green fluorescence detects Ct0861-GFP hyphae. The blue signal corresponds to the autofluorescence of the cell walls. Arrows show the position of the hyphae inside the cells.

\subsection{Ct0861 Increases Maize and Tomato Growth and Yield in Grower-Close Conditions}

In the next step, we assessed the performance of Ct0861 on maize and tomato cultivated under standard grower conditions. In the case of maize, seeds from the commercial variety LG 34.90 were inoculated with three different doses of Ct0861 and sown in a natural soil. Plant emergence and survival measured after 30 days was between $95 \%$ and $98 \%$ and did not differ from the untreated control. For each treatment, the growth of maize plants was first assessed by recording the stem height 
of 80 plants at phenological stage R3. Plants inoculated with Ct0861 were significantly taller than the negative controls (KW test, $X^{2}=33.748, p<0.001$ ) (Table 4). No significant difference in height was observed between the plants inoculated at different doses. Reproductive parameters were evaluated at the end of the plant life cycle. Negative control plants showed yield parameters compatible with the expected yield (12-12.5 t.ha ${ }^{-1}$ ) provided by the seed breeder at the same plant density [32], showing that the experiment was done under optimal growth conditions. The inoculation with Ct0861 had a positive effect on the number of cobs per plant ( $5 \%$ of increase), cob weight per plant ( $7 \%$ to $20 \%$ of increase), and 1000 kernels weight (1\% to $4 \%$ of increase) in a dose-response dependent manner, resulting in a significant increase in yield (kernel weight) per plant between $7 \%$ and $22 \%$, that was highest for plants treated at the highest dose (CtST3-Zm) compared to the control plants (ANOVA, $\mathrm{F}_{3}$ $=4.167, p<0.05$, Table 4). The colonization by Ct0861 was evaluated at harvest by real time PCR in the roots of one plant per plot for CtST3-Zm and negative control (M-Zm) treatments. Ct0861 was detected in $75 \%$ of CtST3-Zm-analyzed plants and it was not detected in any of the M-Zm sampled plants.

Table 4. Effect of Ct0861 in plant growth and yield of maize grown in open field.

\begin{tabular}{ccccccc}
\hline Treatments $^{\mathbf{1}}$ & $\begin{array}{c}\text { Stem } \\
\text { Height (m) }\end{array}$ & $\begin{array}{c}\text { Number of } \\
\text { Cobs Per } \\
\text { Plant }\end{array}$ & $\begin{array}{c}\text { Mean Cob } \\
\text { Weight Per } \\
\text { Plant (g) }\end{array}$ & $\begin{array}{c}\mathbf{1 0 0 0} \\
\text { Kernels } \\
\text { Weight (g) }\end{array}$ & $\begin{array}{c}\text { Mean } \\
\text { Yield·Plant } \\
\text { (g) }\end{array}$ & $\begin{array}{c}\text { Yield }^{\mathbf{1}} \\
\left(\mathbf{t} \cdot \mathbf{h a}^{-\mathbf{1}}\right)\end{array}$ \\
\hline M-Zm & $2.47 \pm 0.24 \mathrm{~b}$ & $1.25 \pm 0.45 \mathrm{a}$ & $198.2 \pm 30.0 \mathrm{a}$ & $381 \pm 18 \mathrm{a}$ & $169.0 \pm 28.8 \mathrm{~b}$ & $12.5 \pm 2.1 \mathrm{~b}$ \\
CtST1-Zm & $2.62 \pm 0.26 \mathrm{a}$ & - & $211.2 \pm 18.4 \mathrm{a}$ & $386 \pm 11 \mathrm{a}$ & $181.6 \pm 15.0 \mathrm{ab}$ & $13.4 \pm 1.1 \mathrm{ab}$ \\
CtST2-Zm & $2.70 \pm 0.21 \mathrm{a}$ & - & $224.4 \pm 26.9 \mathrm{a}$ & $388 \pm 20 \mathrm{a}$ & $191.7 \pm 24.2 \mathrm{ab}$ & $14.1 \pm 1.8 \mathrm{ab}$ \\
CtST3-Zm & $2.63 \pm 0.28 \mathrm{a}$ & $1.31 \pm 0.50 \mathrm{a}$ & $237.3 \pm 30.4 \mathrm{a}$ & $395 \pm 11 \mathrm{a}$ & $206.8 \pm 23.3 \mathrm{a}$ & $15.2 \pm 1.7 \mathrm{a}$ \\
\hline
\end{tabular}

${ }^{1}$ Labels related to different treatments are described in Table 1. Data (means \pm standard deviations) related to stem height $(\mathrm{m})(n=80$ plants, 20 plants per plot) and 1000 kernels weight $(n=4$ plots with 44 plants each) were analyzed by Kruskal-Wallis test with Nemenyi post-hoc test. Data from number of cobs per plant $(n=16$ plants, 4 plants per plot) were analyzed by two sample $t$-test. Data from mean cob weight per plant, mean yield per plant and yield ( $n=4$ plots with 44 plants each) were analyzed by one-way ANOVA with LSD post-hoc test. Different letters within each column indicate significant differences among treatments $(p<0.05)$.

In the case of tomato, the effect of Ct0861 was assayed by applying it either on seeds or by irrigation 10 days after transplanting. Tomato plants were cultivated in substrate-containing pots in a greenhouse using standard conditions for tomato fruit production. Both Ct0861 treatments positively affected dry root weight measured at the end of the crop cycle, which was a significant $2 \%$ higher than in negative controls (ANOVA, $\mathrm{F}_{2}=4.886, p=0.01$; Table 5). Furthermore, tomato plants inoculated with Ct0861 had a significant increase in the number of buds ( $49 \%$ to $64 \%$ increase, KW test, $X^{2}=40.993$ and $61.031, p<0.001)$ and open flowers (20\% to 54\% increase, KW test, $X^{2}=7.0964$ and $\left.33.649, p<0.001\right)$ measured at 12 and 13 weeks post sowing. Fruits were harvested and measurements recorded five times during trial development until the end of the plant life cycle, and data of three regular harvest intervals (Supplementary Table S4) were compared by means of a two-way analysis of variance of aligned rank transformed data (Supplementary Table S5). We observed a significant increase during the productive cycle for all the parameters measured and significant differences between treatments in each harvest interval for the number of fruits per plant (KW test, HI1: $\mathrm{X}^{2}=31.359, p<0.001, \mathrm{HI} 2$ : $\mathrm{X}^{2}=6.9, p=0.032 ; \mathrm{HI} 3: \mathrm{X}^{2}=13.38 ; p=0.0012$ ) and total yield (ANOVA, HI1: $\mathrm{F}_{2}=10.75, p=0.0013$, HI2: $F_{2}=8.047, p=0.018 ; H I 3: F_{2}=10.8 ; p=0.0012$ ) (Figure 3). However, for fruit weight and yield per plant, the significant differences were found at the beginning and the end of the productive period, but not in the middle (Supplementary Table S4). We also found a significant interaction between the factor "harvesting interval" and "treatment" (Supplementary Table S5) that reflects that the differences between treatments were not constant along the productive cycle, but were enhanced at the beginning and at the end, and that these differences depended on the treatment, being more pronounced for the irrigation treatment. This significant interaction is not found for the number of fruits per plant, meaning that the differences between treatments are maintained along the productive cycle. 
Table 5. Effect of Ct0861 in plant growth and yield of tomato grown in a production greenhouse.

\begin{tabular}{|c|c|c|c|c|c|c|c|c|c|}
\hline \multirow{2}{*}{ Treatments $^{1}$} & \multirow{2}{*}{$\begin{array}{c}\text { Root } \\
\text { Weight (g) }\end{array}$} & \multicolumn{2}{|c|}{ N. Buds.Plant ${ }^{-12}$} & \multicolumn{2}{|c|}{ N. Open Flowers.Plant ${ }^{-12}$} & \multirow{2}{*}{$\begin{array}{c}\text { Total Fruits } \\
\text { Plant }^{-1}\end{array}$} & \multirow{2}{*}{$\begin{array}{l}\text { Mean Fruit } \\
\text { Weight (g) }\end{array}$} & \multirow{2}{*}{$\begin{array}{l}\text { Yield. } \\
\text { Plant }^{-1} \\
\text { (kg) }\end{array}$} & \multirow{2}{*}{$\begin{array}{l}\text { Yield } \\
\left(\mathbf{t} \cdot h a^{-1}\right)\end{array}$} \\
\hline & & M1 & M2 & M1 & M2 & & & & \\
\hline M-Sl & $363.5 \pm 11.2 \mathrm{a}$ & $5.1 \pm 1.6 \mathrm{a}$ & $6.6 \pm 1.5 \mathrm{a}$ & $2.9 \pm 1.1 \mathrm{a}$ & $3.5 \pm 1.3 \mathrm{a}$ & $24.8 \pm 1.6 \mathrm{a}$ & $128.5 \pm 2.1 \mathrm{a}$ & $3.2 \pm 0.2 \mathrm{a}$ & $63.5 \pm 2.1 \mathrm{a}$ \\
\hline CtST-Sl & $369.8 \pm 8.1 \mathrm{~b}$ & $7.6 \pm 2.4 \mathrm{~b}$ & $10.8 \pm 3.4 \mathrm{~b}$ & $3.7 \pm 1.3 b$ & $4.8 \pm 1.5 \mathrm{~b}$ & $25.8 \pm 1.6 \mathrm{~b}$ & $130.4 \pm 5.1 \mathrm{~b}$ & $3.4 \pm 0.3 b$ & $67 \pm 2.1 \mathrm{~b}$ \\
\hline CtIR-Sl & $372.0 \pm 9.8 \mathrm{~b}$ & $8.0 \pm 2.4 b$ & $10.7 \pm 2.6 \mathrm{~b}$ & $3.5 \pm 1.7 \mathrm{ab}$ & $5.4 \pm 1.7 \mathrm{~b}$ & $27.1 \pm 2.1 \mathrm{c}$ & $130.4 \pm 2.1 \mathrm{~b}$ & $3.5 \pm 0.3 c$ & $71.1 \pm 1.8 \mathrm{c}$ \\
\hline
\end{tabular}

A

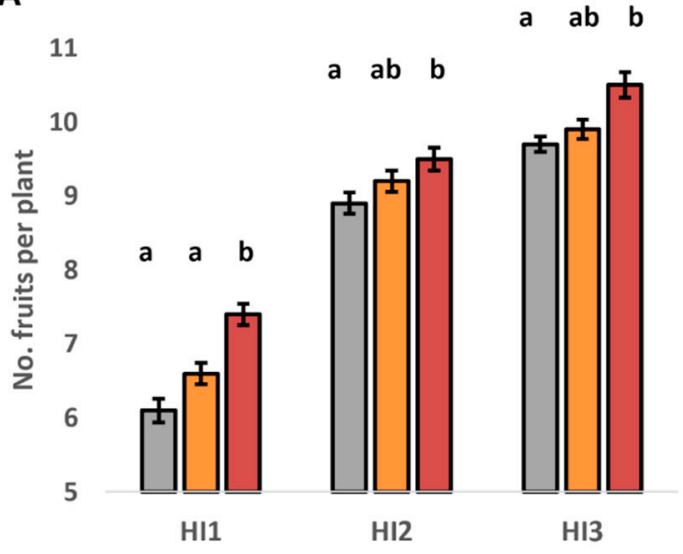

Harvest interval

B

30

28

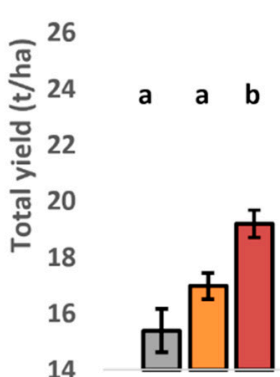

HI1 a a b

a $a b$ b

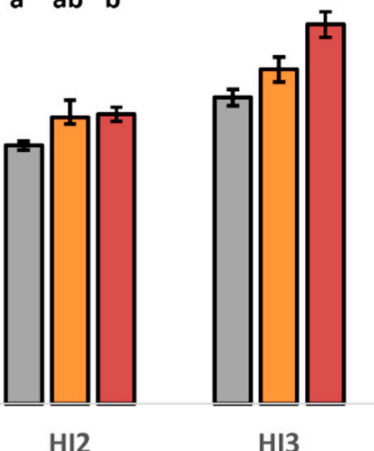

Harvest interval

\section{口 M-SI 口CtST-SI 口CtIR-SI}

Figure 3. Effect of Ct0861 on number of fruits per plant (A) and total yield (B) split by harvest interval (HI) of tomato grown in a production greenhouse. Labels related to different treatments are described in Table 2. Data correspond to a harvest period of 53 days divided in three regular intervals of 17 days. Yields were summed within each harvest interval. The number of fruits per plant ( $n=48$ plants) were analyzed by Kruskal-Wallis test with Nemenyi post-hoc test. Yield (t.ha $\left.{ }^{-1}\right)(n=48$ plants) was analyzed by one-way ANOVA with LSD post-hoc test. Different letters within each harvest interval indicate significant differences among treatments $(p<0.05)$. Error bars represent standard errors.

The total tomato yield was calculated and expressed in $\mathrm{kg}$ per plant and tons per hectare (Table 5), showing a significant increase in total yield $\left(6 \%\right.$ to $12 \%$ increase, ANOVA, $\left.\mathrm{F}_{2}=23.45, p<0.001\right)$ in Ct0861-inoculated tomato plants that was associated with a higher number of fruits produced per plant $\left(4 \%\right.$ to $8 \%$ increase, KW test, $\left.\mathrm{X}^{2}=28.195, p<0.001\right)$ and an increase of the average weight per fruit $\left(1 \%\right.$ increase, $\mathrm{KW}$ test, $\left.\mathrm{X}^{2}=17.26, p<0.001\right)$. The colonization by $\mathrm{Ct} 0861$ for each treatment was evaluated in 20 plants sampled one month after inoculation. Using a real time PCR approach, Ct0861 was detected in 13\% of CtST-Sl plants and 31\% of CtIR-Sl plants. In a second approach, Ct0861 was re-isolated from plant material on PDA plates. In this case, the colonization percentages were 6\% (CtST-Sl) and 81\% (CtIR-S1). There was no correspondence between re-isolation and molecular detection method in CtST-Sl-treated plants, whereas all real time PCR positive plants were also positive by re-isolation in CtIR-Sl-treated plants. Thus, combining the results of the two detection methods, Ct0861 was detected in 19\% of CtST-Sl plants and 81\% of CtIR-Sl plants. In CtST-Sl plants, Ct0861 was only detected in roots, whereas in CtIR-Sl plants, Ct0861 was also detected in the stem. Ct0861 was not detected in any of the mock treated negative controls. Irrigation treatment gave significantly better results in terms of yield and number of fruits when compared to the seed treatment, and this result correlated with a greater detection of the fungus in the plant. This could be due to the higher Ct0861 dose applied in the irrigation treatment $\left(2 \times 10^{6}\right.$ conidia.plant $\left.^{-1}\right)$ than in the seed treatment $\left(10^{5}\right.$ conidia $\cdot$ seed $\left.^{-1}\right)$. 


\section{Discussion}

In this work, we provide the first evidence of the ability of the fungal endophyte $C$. tofieldiae to colonize maize and tomato plants and to induce plant growth, fertility, and yield increase in greenhouse and open-field trials; expanding previous knowledge obtained with the model plant A. thaliana at laboratory conditions and bringing this knowledge closer to its agricultural application. Hiruma et al. [20] demonstrated that Ct0861, isolated from a wild A. thaliana plant in central Spain, establishes a mutualistic interaction with its host, increasing Pi uptake of the plant and promoting its growth under laboratory conditions. C. tofieldiae is a fungus that is distributed worldwide and has been isolated from many different wild plant species, including both monocots and dicots, growing in diverse ecosystems [22-25]. These characteristics led us to hypothesize about the possible extension of its beneficial effect to other hosts and its application to commercial crops. It has been proposed that the ability of fungal endophytes to confer benefits to a wide range of hosts may be the rule rather than the exception [33]. However, despite increasing evidence of the positive effects of the plant microbiome, application transfer from the lab to the field across different plant species is still scarce $[7,8,10]$. A substantial problem hampering the agricultural adoption of beneficial microorganisms is the lack of reproducibility and consistence of their performance under varying environments, or the insufficient persistence of their effect along the whole crop cycle $[7,11]$.

The genus Colletotrichum (ascomycete teleomorph Glomerella) is a large and widespread group, with around 40 recognized species and species aggregates, many of them plurivorous, from a wide range of host plants [34]. Some Colletotrichum species are important plant pathogens, producing anthracnose symptoms in tropical and subtropical crops [35]. However, there is increasing evidence of the high diversity and frequency of endophytic Colletotrichum species, some of them having beneficial effects on the host [36-43], and being the endophytic lifestyle associated to a wide host range [44]. The genomic comparison of different isolates of $C$. tofieldiae with related species suggested that this species evolved from pathogenic ancestors by reducing its set of candidate secreted effector proteins (CSEPs) and the expansion of chitin-binding and secondary metabolism-related protein families [21]. Indeed, the frontier between pathogens and endophytes is frequently blurred [45-47], and there are several examples where the outcome of the interaction depends on few environmental or genetic factors [48], even for mycorrhiza relationships [49,50]. Although there is some evidence showing that parasitism predates other lifestyles [21,51,52], it is still hard to draw general conclusions. However, the fact is that the type of interaction with the plant is a polyphyletic trait and, besides Colletotrichum, there are many other genera and even species that contain both pathogens and endophytes [53], such as Phoma, Plectosphaerella, and, notably, Fusarium [54-56]. Belonging to closely related species, pathogenic and endophytic strains may share most of their genomes and interaction mechanisms with the plant [48,57].

We have shown that $\mathrm{Ct} 0861$ colonizes maize and tomato seedlings in vitro without causing disease symptoms and promoting root and shoot growth. Confocal microscopy images and the re-isolation of Ct0861 from surface-sterilized tomato cotyledons and maize coleoptile fragments suggest that the fungus penetrates first the radicle tissues and then moves systemically to reach the upper parts of the plant. Our results are in agreement with previous studies in A. thaliana where Ct0861 colonized Arabidopsis roots and progressed to the shoot by the root central cylinder, but was not able to penetrate into the plant when it was inoculated on the leaves [20]. These results suggest that Ct0861 employs similar mechanisms to enter and colonize distant plant host species.

Our study reveals Ct0861 as a generalist able to improve yield in both monocotyledonous and dicotyledonous plant species, such as maize and tomato. There are some other examples of beneficial fungi such as Glomus spp. and other arbuscular mycorrhizal fungi (AMF) [58-63] or the endophyte $P$. indica [64] that also have wide host ranges and show beneficial effects under different conditions. It has been shown that $P$. indica promotes vegetative growth and early flowering, improves seed germination, and increases yield in multiple plant species [13]. Similarly to Ct0861, P. indica has been reported to increase plant fresh biomass of four-week maize [65] and tomato plants in pots grown in a 
greenhouse [66,67]. However, regarding yield increase, studies with P. indica on tomato are contrasting, and the effect obtained with this endophyte seems to depend on the moment of observation. At an early fruit production phase, the yield tends to be higher in colonized plants [66,67], while other studies have shown that the total fruit production and yield does not differ from the controls [68]. These results are similar to the effect found with dark septate endophytes (DSE) in tomato [69] and suggest an early or accelerated development of colonized plants rather than an increase of the total yield. Thus, it is important to measure the yield at the end of the plant life cycle in order to distinguish a true increase in yield from an effect on the development. In a recent study, 28 fungal endophytic isolates of 22 species from different crop plants were tested for their ability to promote tomato growth and yield [70]. All isolates significantly increased plant biomass parameters and six of them improved tomato fruit yield at the end of the crop cycle. Here, we show that Ct0861 improves tomato plant fertility at early reproductive stages by inducing the production of buds and flowers and enhancing yield by increasing the number of fruits and fruit weight over the whole plant life cycle, although the observable effect is not constant, being intensified at the beginning and at the end of the productive period. Our findings showed that Ct0861 induces an increase in maize yield associated to an increase in kernel weight and a higher average number of cobs per plant. AMF colonization can also increase kernel size in maize in addition to yield [60]. There are several studies on the associations of maize in field with AMF, some of them providing contrasting results in terms of yield increase [11,42,59,71,72]. However, although there is abundant work on the description of the factors affecting the composition of endophytic communities [73-76], only few data on the effect of fungal endophytes in open-field trials are available [77]. Given that maize is one of the most cultivated arable crops worldwide and the potential advantages of the utilization of fungal endophytes in modern agriculture, further investigations should focus on the interactions of this crop with these fungi and their mode of action.

We detected Ct 0861 by real time PCR in the roots of $75 \%$ of the inoculated maize plants at harvest, which indicates that this fungus was able to survive throughout the whole plant life cycle in most of the plants. The molecular detection in the roots of tomato plants, however, was much lower, and depended on the inoculation method, with $13 \%$ positive seed-inoculated plants and $31 \%$ positive plants inoculated by irrigation. A higher percentage of colonized tomato plants was detected by the classical re-isolation method, reaching $81 \%$ of positive plants among those inoculated by irrigation. The lower detection capacity of real time PCR compared with re-isolation is indicative of a low amount of Ct0861 in the plant, below the detection threshold of the PCR method. Re-isolation method was more sensitive probably because very low amounts of fungus in the plant become evident when growing in optimal culture conditions. This low amount of fungus in the plant suggests that Ct0861 is not a very invasive fungus, although more studies are needed to ascertain the fungal growth dynamics during plant life cycle and its survival ability in the field. Irrigation treatment gave better results for the number of fruits per plant and yield, which correlated with the higher percentage of colonized plants. The better results of this treatment could be due to the higher Ct0861 dose applied $\left(2 \times 10^{6}\right.$ conidia.plant $\left.{ }^{-1}\right)$ compared with the seed treatment $\left(10^{5}\right.$ conidia.plant $\left.^{-1}\right)$, rather than the method itself. A dose-response effect of Ct0861 was indeed evident in maize, with a significantly higher yield of plants inoculated with the higher dose.

The already described mechanisms governing the beneficial effect of Ct0861 in Arabidopsis are regulated by Pi availability [20]. Our results with maize and tomato do not seem to be dependent on the nutritional status of the plant, since in vitro, greenhouse and field experiments were performed under optimized conditions. Thus, the beneficial effect observed in this work suggests the existence of another mode of action than described in Arabidopsis. Different modes of action have also been described for other beneficial fungi. The fungal endophyte Mucor $s p$. has been reported to positively regulate the growth of Arabidopsis under optimal nutrient and water supply [78]. The results suggested that the colonization of the endophytic fungus improved plant $\mathrm{CO}_{2}$ assimilation and water use efficiency and optimized photosynthesis and carbon uptake triggered by the upregulation of the expression of genes involved in typical photosynthesis response to carbon deficiency. A similar study 
revealed that maize root colonization by Trichoderma virens increased the photosynthetic rates in leaves because of the sucrolytic activity in the fungal cells at the root [79]. The enrichment for secondary metabolite-encoding genes in Ct0861 genome in comparison to other endophytic and mycorrhizal fungi [21] and consequently, the secretion of fungal metabolites, might play a role in the beneficial effect observed in inoculated plants. Such mechanisms have also been reported for $P$. indica, which relies on phytohormone production, such as auxin [80], or on the modulation of phytohormone signaling [81] and related gene expression $[82,83]$ to produce an accelerated root development, which finally induces general plant vegetative growth promotion [84]. Moreover, the abscisic acid pathway in Arabidopsis, as a response to $P$. indica, improved plant growth via calcium [85], phosphoinositide, and certain protein kinases [86]. Enhanced protection against oxidative stress via production of antioxidants or its induction in the host seems also to be a common mechanism in mutualistic interactions between plants and fungal endophytes, especially under stress conditions $[87,88]$. Several studies reported that tolerance to different abiotic stresses induced by $P$. indica is associated to an increase in antioxidant activity [89-92]. The effect of Ct0861 on crops undergoing abiotic stress is currently being investigated. Taken all together, we hypothesize that several mechanisms, rather than a unique mechanism, might contribute to the benefits obtained by the plant from its interaction with Ct0861.

In summary, after it has been shown that the fungal endophyte $C$. tofieldiae $\mathrm{Ct} 0861$ confers fitness benefits in the model plant $A$. thaliana [20], we deliver the first example of the potential application of this fungus in agriculture and horticulture. However, the mechanisms whereby this fungus confers such benefits to these crops remain unknown and are subject to future research. Additional efforts are also required to decipher the role and effect of Ct0861 in multitrophic interactions with changing environmental conditions such as climate, soil type, microbiota, etc.- - by means of further experiments in different locations and different years studying the dynamics of the colonization of the plants in the field, the persistence in the plant, and the interaction with the microbiome-in order to be able to develop predictive models to achieve optimal exploitation of Ct0861-based plant growth and production in agriculture complying with current socio-economic needs.

\section{Patents}

S.S. is inventor of patent WO2015/092104 on the commercial use of isolate Ct0861 assigned to UPM and PlantResponse Biotech, S.L. and licensed by PlantResponse Biotech, S.L.

Supplementary Materials: The following are available online at http://www.mdpi.com/2073-4395/10/10/1493/s1, Figure S1. Conidiomata acervular and setae formed on surface sterilized cut off tissue fragments of maize (A: root, B: mesocotyl, C: apical tissues of coleoptile) and tomato (D: root, E: hypocotyl, F: cotyledon) incubated in moist chamber for seven days, Table S1. Physico-chemical properties of the soil at the experimental site in Pilar de la Horadada, Spain, analyzed at pre-sowing and post-harvesting, Table S2. Physico-chemical properties of the substrates used in the tomato greenhouse experiment, Table S3. Fertigation program applied to tomato trial in production greenhouse, Table S4. Effect of Ct0861 on yield parameters split by harvest interval of tomato grown in a production greenhouse, Table S5. Two Factors Analysis of Variance of Aligned Rank Transformed Data of effect of Ct0861 on yield parameters split by harvest interval of tomato grown in a production greenhouse, Video S1. Animation of a stack of confocal sections across a maize root inoculated with Ct0861-GFP, spanning $25 \mu \mathrm{m}$, obtained on a Zeiss 880 microscope, Video S2. Animation of a stack of confocal sections across a tomato root inoculated with Ct0861-GFP, spanning $25 \mu \mathrm{m}$, obtained on a Zeiss 880 microscope.

Author Contributions: Conceptualization, S.D.-G., P.M., J.K., F.B. and S.S.; Methodology, S.D.-G., P.M., J.K., P.G.-M., F.B. and S.S.; Validation, S.D.-G., P.M., R.S. and C.A.; Formal analysis, S.D.-G. and P.M.; Investigation, S.D.-G, P.M., R.S., C.A. and P.G.-M.; Resources, J.K., F.B. and S.S.; Writing-original draft preparation, S.D.-G., F.B. and S.S.; Writing-review and editing, S.D.-G., P.M., J.K., P.G.-M., F.B. and S.S.; Visualization, S.D.-G., P.M. and P.G.-M.; Supervision, F.B. and S.S.; Project administration, F.B. and S.S.; Funding acquisition, F.B. and S.S. All authors have read and agreed to the published version of the manuscript.

Funding: This research was funded by Programa Estatal de Promoción del Talento y su Empleabilidad en I+D+I of Ministerio de Ciencia, Innovación y Universidades of the Spanish Government, grant number DI-15-07906.

Acknowledgments: We thank Professor Paul Schulze-Lefert from the Max Planck Institute for Plant Breeding Research for kindly providing the GFP transformed strain Ct0861-GFP. 
Conflicts of Interest: S.D.-G., P.M., R.S., C.A., J.K. and F.B. are employees of the company PlantResponse Biotech SL (PRB). S.S. is inventor of patent WO2015/092104 on the commercial use of isolate Ct0861 assigned to UPM and PlantResponse Biotech, S.L. and licensed by PlantResponse Biotech, S.L. The authors declare no other competing interests.

\section{References}

1. Bhardwaj, D.; Ansari, M.; Sahoo, R.; Tuteja, N. Biofertilizers function as key player in sustainable agriculture by improving soil fertility, plant tolerance and crop productivity. Microb. Cell Fact. 2014, 13, 66. [CrossRef]

2. Bailey-Serres, J.; Parker, J.E.; Ainsworth, E.A.; Oldroyd, G.E.D.; Schroeder, J.I. Genetic strategies for improving crop yields. Nature 2019, 575, 109-118. [CrossRef] [PubMed]

3. Foley, J.A.; Ramankutty, N.; Brauman, K.A.; Cassidy, E.S.; Gerber, J.S.; Johnston, M.; Mueller, N.D.; O'Connell, C.; Ray, D.K.; West, P.C.; et al. Solutions for a cultivated planet. Nature 2011, 478, 337-342. [CrossRef] [PubMed]

4. Howden, S.M.; Soussana, J.F.; Tubiello, F.N.; Chhetri, N.; Dunlop, M.; Meinke, H. Adapting agriculture to climate change. Proc. Natl. Acad. Sci. USA 2007, 104, 19691-19696. [CrossRef] [PubMed]

5. Pingali, P.L. Green Revolution: Impacts, limits, and the path ahead. Proc. Natl. Acad. Sci. USA 2012, 109, 12302-12308. [CrossRef] [PubMed]

6. Organic Materials Review Institute OMRI. Products List. Available online: https://www.omri.org/sites/ default/files/opl_pdf/CropByProduct-NOP.pdf (accessed on 25 October 2019).

7. Le Cocq, K.; Gurr, S.J.; Hirsch, P.R.; Mauchline, T.H. Exploitation of endophytes for sustainable agricultural intensification. Mol. Plant Pathol. 2017, 18, 469-473. [CrossRef]

8. $\quad$ Finkel, O.M.; Castrillo, G.; Herrera Paredes, S.; Salas González, I.; Dangl, J.L. Understanding and exploiting plant beneficial microbes. Curr. Opin. Plant Biol. 2017, 38, 155-163. [CrossRef]

9. Sessitsch, A.; Mitter, B. 21st century agriculture: Integration of plant microbiomes for improved crop production and food security. Microb. Biotechnol. 2015, 8, 32-33. [CrossRef]

10. Sergaki, C.; Lagunas, B.; Lidbury, I.; Gifford, M.L.; Schäfer, P. Challenges and approaches in microbiome research: From fundamental to applied. Front. Plant Sci. 2018, 9, 1205. [CrossRef]

11. Bender, S.F.; Schlaeppi, K.; Held, A.; Van der Heijden, M.G.A. Establishment success and crop growth effects of an arbuscular mycorrhizal fungus inoculated into Swiss corn fields. Agric. Ecosyst. Environ. 2019, 273, 13-24. [CrossRef]

12. Rodriguez, R.J.; White, J.F.; Arnold, A.E.; Redman, R.S. Fungal endophytes: Diversity and functional roles. New Phytol. 2009, 182, 314-330. [CrossRef] [PubMed]

13. Hardoim, P.R.; van Overbeek, L.S.; Berg, G.; Pirttilä, A.M.; Compant, S.; Campisano, A.; Döring, M.; Sessitsch, A. The hidden world within plants: Ecological and evolutionary considerations for defining functioning of microbial endophytes. Microbiol. Mol. Biol. Rev. 2015, 79, 293-320. [CrossRef] [PubMed]

14. Harrison, J.G.; Griffin, E.A. The diversity and distribution of endophytes across biomes, plant phylogeny and host tissues: How far have we come and where do we go from here? Environ. Microbiol. 2020, 22, 2107-2123. [CrossRef] [PubMed]

15. Lugtenberg, B.J.J.; Caradus, J.R.; Johnson, L.J. Fungal endophytes for sustainable crop production. FEMS Microbiol. Ecol. 2016, 92. [CrossRef] [PubMed]

16. Yan, L.; Zhu, J.; Zhao, X.; Shi, J.; Jiang, C.; Shao, D. Beneficial effects of endophytic fungi colonization on plants. Appl. Microbiol. Biotechnol. 2019, 103, 3327-3340. [CrossRef]

17. Wani, Z.A.; Ashraf, N.; Mohiuddin, T.; Riyaz-Ul-Hassan, S. Plant-endophyte symbiosis, an ecological perspective. Appl. Microbiol. Biotechnol. 2015, 99, 2955-2965. [CrossRef]

18. Suryanarayanan, T.S.; Gopalan, V.; Shaanker, R.U.; Sengupta, A.; Ravikanth, G. Translating endophyte research to applications: Prospects and challenges. In Diversity and Benefits of Microorganisms from the Tropics; de Azevedo, J., Quecine, M., Eds.; Springer International Publishing: Cham, Switzerland, 2017; pp. 343-365. ISBN 9783319558042.

19. Griffin, E.A.; Carson, W.P. Tree endophytes: Cryptic drivers of tropical forest diversity. In Endophytes of Forest Trees; Pirttilä, A., Frank, A., Eds.; Springer: Cham, Switzerland, 2018; pp. 63-103. ISBN 9783319898339.

20. García, E.; Alonso, Á.; Platas, G.; Sacristán, S. The endophytic mycobiota of Arabidopsis thaliana. Fungal Divers. 2013, 60, 71-89. [CrossRef] 
21. Hiruma, K.; Gerlach, N.; Sacristán, S.; Nakano, R.T.; Hacquard, S.; Kracher, B.; Neumann, U.; Ramírez, D.; Bucher, M.; O'Connell, R.J.; et al. Root endophyte colletotrichum tofieldiae confers plant fitness benefits that are phosphate status dependent. Cell 2016, 165, 464-474. [CrossRef]

22. Hacquard, S.; Kracher, B.; Hiruma, K.; Münch, P.C.; Garrido-Oter, R.; Thon, M.R.; Weimann, A.; Damm, U.; Dallery, J.F.; Hainaut, M.; et al. Survival trade-offs in plant roots during colonization by closely related beneficial and pathogenic fungi. Nat. Commun. 2016, 7, 11362. [CrossRef]

23. Damm, U.; Woudenberg, J.H.C.; Cannon, P.F.; Crous, P.W. Colletotrichum species with curved conidia from herbaceous hosts. Fungal Divers. 2009, 39, 45-87.

24. Tao, G.; Liu, Z.Y.; Liu, F.; Gao, Y.H.; Cai, L. Endophytic Colletotrichum species from Bletilla ochracea (Orchidaceae), with descriptions of seven new speices. Fungal Divers. 2013, 61, 139-164. [CrossRef]

25. Jayawardena, R.S.; Hyde, K.D.; Damm, U.; Cai, L.; Liu, M.; Li, X.H.; Zhang, W.; Zhao, W.S.; Yan, J.Y. Notes on currently accepted species of Colletotrichum. Mycosphere 2016, 7, 1192-1260. [CrossRef]

26. Shivas, R.G.; Tan, Y.P.; Edwards, J.; Dinh, Q.; Maxwell, A.; Andjic, V.; Liberato, J.R.; Anderson, C.; Beasley, D.R.; Bransgrove, K.; et al. Colletotrichum species in Australia. Australas. Plant Pathol. 2016, 45, 447-464. [CrossRef]

27. FAOSTAT Database. Available online: http://www.fao.org/faostat/es/\#data/QC (accessed on 25 October 2019).

28. Ministerio de Agricultura, Pesca y Alimentación. Superficies y Producciones Anuales de Cultivos. Datos Avances de Cereales. Available online: https://www.mapa.gob.es/es/estadistica/temas/estadisticas-agrarias/ agricultura/superficies-producciones-anuales-cultivos/ (accessed on 25 October 2019).

29. Roca, A.; Pizarro-Tobías, P.; Udaondo, Z.; Fernández, M.; Matilla, M.A.; Molina-Henares, M.A.; Molina, L.; Segura, A.; Duque, E.; Ramos, J.-L. Analysis of the plant growth-promoting properties encoded by the genome of the rhizobacterium Pseudomonas putida BIRD-1. Environ. Microbiol. 2013, 15, 780-794. [CrossRef] [PubMed]

30. Agencia Estatal de Meteorología (Ministerio de Medio Ambiente y Medio Rural y Marino de España) and Instituto de Meteorologia de Portugal. Iberian Climate Atlas. Available online: http://www.aemet.es/documentos/es/ conocermas/recursos_en_linea/publicaciones_y_estudios/publicaciones/Atlas-climatologico/Atlas.pdf (accessed on 25 October 2019).

31. Agencia Estatal de Meteorología (Ministerio de Medio Ambiente y Medio Rural y Marino). Servicios Climáticos: Datos Climatológicos Normales de la Estación de San Javier Aeropuerto (Murcia). Available online: http://www.aemet.es/es/serviciosclimaticos/datosclimatologicos/valoresclimatologicos?l=7031\&k= undefined (accessed on 25 October 2019).

32. Instituto Murciano de Investigación y Desarrollo Agrario y Alimentario (IMIDA). Data from: Sistema de Información Agrometeorológica de la Región de Murcia (SIAM). Available online: http://siam.imida.es/apex/ $f ? p=101: 46: 1821222586473642$ (accessed on 20 August 2004).

33. Limagrain Ibérica. La densidad óptima. In Maíz y Girasol, Catálogo 2018; Limagrain Ibérica: Navarra, Spain, 2018; pp. 34-35.

34. Cannon, P.F.; Damm, U.; Johnston, P.R.; Weir, B.S. Colletotrichum-Current status and future directions. Stud. Mycol. 2012, 73, 181-213. [CrossRef] [PubMed]

35. Hyde, K.D.; Cai, L.; Cannon, P.F.; Crouch, J.A.; Crous, P.W.; Damm, U.; Goodwin, P.H.; Chen, H.; Johnston, P.R.; Jones, E.; et al. Colletotrichum-Names in current use. Fungal Divers. 2009, 39, 147-182.

36. Lu, G.; Cannon, P.F.; Reid, A.; Simmons, C.M. Diversity and molecular relationships of endophytic Colletotrichum isolates from the Iwokrama Forest Reserve, Guyana. Mycol. Res. 2004. [CrossRef]

37. Götz, M.; Nirenberg, H.; Krause, S.; Wolters, H.; Draeger, S.; Buchner, A.; Lottmann, J.; Berg, G.; Smalla, K. Fungal endophytes in potato roots studied by traditional isolation and cultivation-independent DNA-based methods. FEMS Microbiol. Ecol. 2006. [CrossRef]

38. Hyde, K.D.; Soytong, K. The fungal endophyte dilemma. Fungal Divers. 2008, 33, 163-173.

39. Rakotoniriana, E.F.; Munaut, F.; Decock, C.; Randriamampionona, D.; Andriambololoniaina, M.; Rakotomalala, T.; Rakotonirina, E.J.; Rabemanantsoa, C.; Cheuk, K.; Ratsimamanga, S.U.; et al. Endophytic fungi from leaves of Centella asiatica: Occurrence and potential interactions within leaves. Antonie van Leeuwenhoek Int. J. Gen. Mol. Microbiol. 2008. [CrossRef]

40. Rojas, E.I.; Rehner, S.A.; Samuels, G.J.; Van Bael, S.A.; Herre, E.A.; Cannon, P.; Chen, R.; Pang, J.; Wang, R.; Zhang, Y.; et al. Colletotrichum gloeosporioides s.l. associated with Theobroma cacao and other plants in Panamá: Multilocus phylogenies distinguish host-associated pathogens from asymptomatic endophytes. Mycologia 2010. [CrossRef] [PubMed] 
41. Gonzaga, L.L.; Costa, L.E.O.; Santos, T.T.; Araújo, E.F.; Queiroz, M.V. Endophytic fungi from the genus Colletotrichum are abundant in the Phaseolus vulgaris and have high genetic diversity. J. Appl. Microbiol. 2015, 118, 485-496. [CrossRef] [PubMed]

42. Miransari, M.; Bahrami, H.A.; Rejali, F.; Malakouti, M.J.; Torabi, H. Using arbuscular mycorrhiza to reduce the stressful effects of soil compaction on corn (Zea mays L.) growth. Soil Biol. Biochem. 2007, 39, 2014-2026. [CrossRef]

43. Mejía, L.C.; Herre, E.A.; Sparks, J.P.; Winter, K.; García, M.N.; Van Bael, S.A.; Stitt, J.; Shi, Z.; Zhang, Y.; Guiltinan, M.J.; et al. Pervasive effects of a dominant foliar endophytic fungus on host genetic and phenotypic expression in a tropical tree. Front. Microbiol. 2014, 5, 479. [CrossRef] [PubMed]

44. Redman, R.S.; Dunigan, D.D.; Rodriguez, R.J. Fungal symbiosis from mutualism to parasitism: Who controls the outcome, host or invader? New Phytol. 2001, 151, 705-716. [CrossRef]

45. Schulz, B.; Boyle, C. The endophytic continuum. Mycol. Res. 2005, 109, 661-686. [CrossRef]

46. Kogel, K.-H.; Franken, P.; Hückelhoven, R. Endophyte or parasite-What decides? Curr. Opin. Plant Biol. 2006, 9, 358-363. [CrossRef]

47. Zeilinger, S.; Gupta, V.K.; Dahms, T.E.S.; Silva, R.N.; Singh, H.B.; Upadhyay, R.S.; Gomes, E.V.; Tsui, C.K.M.; Chandra Nayak, S. Friends or foes? Emerging insights from fungal interactions with plants. FEMS Microbiol. Rev. 2016, 40, 182-207. [CrossRef]

48. Brader, G.; Compant, S.; Vescio, K.; Mitter, B.; Trognitz, F.; Ma, L.-J.; Sessitsch, A. Ecology and genomic insights into plant-pathogenic and plant-nonpathogenic endophytes. Annu. Rev. Phytopathol. 2017. [CrossRef]

49. Johnson, N.C.; Graham, J.H.; Smith, F.A. Functioning of mycorrhizal associations along the mutualism-parasitism continuum. New Phytol. 1997, 135, 575-585. [CrossRef]

50. Murata, H.; Nakano, S.; Yamanaka, T.; Shimokawa, T.; Abe, T.; Ichida, H.; Hayashi, Y.; Tahara, K.; Ohta, A. Conversion from mutualism to parasitism: A mutant of the ectomycorrhizal agaricomycete Tricholoma matsutake that induces stunting, wilting, and root degeneration in seedlings of its symbiotic partner, Pinus densiflora, in vitro. Botany 2019. [CrossRef]

51. Kohler, A.; Kuo, A.; Nagy, L.G.; Morin, E.; Barry, K.W.; Buscot, F.; Canbäck, B.; Choi, C.; Cichocki, N.; Clum, A.; et al. Convergent losses of decay mechanisms and rapid turnover of symbiosis genes in mycorrhizal mutualists. Nat. Genet. 2015. [CrossRef] [PubMed]

52. Xu, X.-H.; Su, Z.-Z.; Wang, C.; Kubicek, C.P.; Feng, X.-X.; Mao, L.-J.; Wang, J.-Y.; Chen, C.; Lin, F.-C.; Zhang, C.-L. The rice endophyte Harpophora oryzae genome reveals evolution from a pathogen to a mutualistic endophyte. Sci. Rep. 2015, 4, 5783. [CrossRef] [PubMed]

53. Rashmi, M.; Kushveer, J.S.; Sarma, V.V. A worldwide list of endophytic fungi with notes on ecology and diversity. Mycosphere 2019, 10, 798-1079. [CrossRef]

54. Bacon, C.W.; Glenn, A.E.; Yates, I.E. Fusarium verticillioides: Managing the endophytic association with maize for reduced fumonisins accumulation. Toxin Rev. 2008, 27, 411-446. [CrossRef]

55. Šišić, A.; Baćanović-Šišić, J.; Al-Hatmi, A.M.S.; Karlovsky, P.; Ahmed, S.A.; Maier, W.; De Hoog, G.S.; Finckh, M.R. The "forma specialis" issue in Fusarium: A case study in Fusarium solani f. sp. pisi. Sci. Rep. 2018. [CrossRef]

56. Skiada, V.; Faccio, A.; Kavroulakis, N.; Genre, A.; Bonfante, P.; Papadopoulou, K.K. Colonization of legumes by an endophytic Fusarium solani strain FsK reveals common features to symbionts or pathogens. Fungal Genet. Biol. 2019. [CrossRef]

57. Fesel, P.H.; Zuccaro, A. Dissecting endophytic lifestyle along the parasitism/mutualism continuum in Arabidopsis. Curr. Opin. Microbiol. 2016, 32, 103-112. [CrossRef]

58. Nzanza, B.; Marais, D.; Soundy, P. Yield and nutrient content of tomato (Solanum lycopersicum L.) as influenced by Trichoderma harzianum and Glomus mosseae inoculation. Sci. Hortic. 2012. [CrossRef]

59. Ortas, I. The effect of mycorrhizal fungal inoculation on plant yield, nutrient uptake and inoculation effectiveness under long-term field conditions. Field Crop. Res. 2012. [CrossRef]

60. Berta, G.; Copetta, A.; Gamalero, E.; Bona, E.; Cesaro, P.; Scarafoni, A.; D’Agostino, G. Maize development and grain quality are differentially affected by mycorrhizal fungi and a growth-promoting pseudomonad in the field. Mycorrhiza 2014, 24, 161-170. [CrossRef] [PubMed]

61. Rouphael, Y.; Franken, P.; Schneider, C.; Schwarz, D.; Giovannetti, M.; Agnolucci, M.; Pascale, S.; De Bonini, P.; Colla, G. Arbuscular mycorrhizal fungi act as biostimulants in horticultural crops. Sci. Hortic. 2015, 196, 91-108. [CrossRef] 
62. van der Heijden, M.G.A.; Martin, F.M.; Selosse, M.-A.; Sanders, I.R. Mycorrhizal ecology and evolution: The past, the present, and the future. New Phytol. 2015, 205, 1406-1423. [CrossRef] [PubMed]

63. Polcyn, W.; Paluch-Lubawa, E.; Lehmann, T.; Mikuła, R. Arbuscular mycorrhiza in highly fertilized maize cultures alleviates short-term drought effects but does not improve fodder yield and quality. Front. Plant Sci. 2019. [CrossRef] [PubMed]

64. Qiang, X.; Weiss, M.; Kogel, K.H.; Schäfer, P. Piriformospora indica-a mutualistic basidiomycete with an exceptionally large plant host range. Mol. Plant Pathol. 2012. [CrossRef]

65. Varma, A.; Savita, V.; Sahay, N.; Butehorn, B.; Franken, P. Piriformospora indica, a cultivable plant-growth-promoting root endophyte. Appl. Environ. Microbiol. 1999, 65, 2741-2744. [CrossRef]

66. Fakhro, A.; Andrade-Linares, D.R.; von Bargen, S.; Bandte, M.; Büttner, C.; Grosch, R.; Schwarz, D.; Franken, P. Impact of Piriformospora indica on tomato growth and on interaction with fungal and viral pathogens. Mycorrhiza 2010, 20, 191-200. [CrossRef]

67. Sarma, M.V.R.K.; Kumar, V.; Saharan, K.; Srivastava, R.; Sharma, A.K.; Prakash, A.; Sahai, V.; Bisaria, V.S. Application of inorganic carrier-based formulations of fluorescent pseudomonads and Piriformospora indica on tomato plants and evaluation of their efficacy. J. Appl. Microbiol. 2011, 111, 456-466. [CrossRef]

68. Andrade-Linares, D.R.; Müller, A.; Fakhro, A.; Schwarz, D.; Franken, P. Impact of Piriformospora indica on Tomato. In Piriformospora indica; Varma, A., Kost, G., Oelmüller, R., Eds.; Springer: Berlin/Heidelberg, Germany, 2013; pp. 107-117.

69. Andrade-Linares, D.R.; Grosch, R.; Franken, P.; Rexer, K.-H.; Kost, G.; Restrepo, S.; de Garcia, M.C.C.; Maximova, E. Colonization of roots of cultivated Solanum lycopersicum by dark septate and other ascomycetous endophytes. Mycologia 2011, 103, 710-721. [CrossRef]

70. Xia, Y.; Sahib, M.R.; Amna, A.; Opiyo, S.O.; Zhao, Z.; Gao, Y.G. Culturable endophytic fungal communities associated with plants in organic and conventional farming systems and their effects on plant growth. Sci. Rep. 2019. [CrossRef]

71. Kabir, Z.; O'Halloran, I.P.; Fyles, J.W.; Hamel, C. Dynamics of the mycorrhizal symbiosis of corn (Zea mays L.): Effects of host physiology, tillage practice and fertilization on spatial distribution of extra-radical mycorrhizal hyphae in the field. Agric. Ecosyst. Environ. 1998. [CrossRef]

72. Liu, A.; Hamel, C.; Hamilton, R.I.; Smith, D.L. Mycorrhizae formation and nutrient uptake of new corn (Zea mays L.) hybrids with extreme canopy and leaf architecture as influenced by soil N and P levels. Plant Soil 2000. [CrossRef]

73. Pan, J.J.; Baumgarten, A.M.; May, G. Effects of host plant environment and Ustilago maydis infection on the fungal endophyte community of maize (Zea mays). New Phytol. 2008. [CrossRef] [PubMed]

74. Da Silva, K.J.; de Armas, R.D.; Soares, C.R.F.S.; Ogliari, J.B. Communities of endophytic microorganisms in different developmental stages from a local variety as well as transgenic and conventional isogenic hybrids of maize. World J. Microbiol. Biotechnol. 2016. [CrossRef] [PubMed]

75. Yu, P.; Wang, C.; Baldauf, J.A.; Tai, H.; Gutjahr, C.; Hochholdinger, F.; Li, C. Root type and soil phosphate determine the taxonomic landscape of colonizing fungi and the transcriptome of field-grown maize roots. New Phytol. 2018. [CrossRef]

76. Brisson, V.L.; Schmidt, J.E.; Northen, T.R.; Vogel, J.P.; Gaudin, A.C.M. Impacts of maize domestication and breeding on rhizosphere microbial community recruitment from a nutrient depleted agricultural soil. Sci. Rep. 2019. [CrossRef] [PubMed]

77. Wallace, J.G.; May, G. Endophytes: The other maize genome. In The Maize Genome; Bennetzen, J.L., Flint-Garcia, S., Hirsch, C.N., Tuberosa, R., Eds.; Springer: Cham, Switzerland, 2018; pp. 213-246.

78. Rozpądek, P.; Nosek, M.; Domka, A.; Ważny, R.; Jędrzejczyk, R.; Tokarz, K.; Pilarska, M.; Niewiadomska, E.; Turnau, K. Acclimation of the photosynthetic apparatus and alterations in sugar metabolism in response to inoculation with endophytic fungi. Plant. Cell Environ. 2019, 42, 1408-1423. [CrossRef]

79. Vargas, W.A.; Mandawe, J.C.; Kenerley, C.M. Plant-derived sucrose is a key element in the symbiotic association between Trichoderma virens and maize plants. Plant Physiol. 2009. [CrossRef]

80. Sirrenberg, A.; Göbel, C.; Grond, S.; Czempinski, N.; Ratzinger, A.; Karlovsky, P.; Santos, P.; Feussner, I.; Pawlowski, K. Piriformospora indica affects plant growth by auxin production. Physiol. Plant. 2007. [CrossRef]

81. Barazani, O.; Von Dahl, C.C.; Baldwin, I.T. Sebacina vermifera promotes the growth and fitness of Nicotiana attenuata by inhibiting ethylene signaling. Plant Physiol. 2007. [CrossRef] 
82. Schäfer, P.; Pfiffi, S.; Voll, L.M.; Zajic, D.; Chandler, P.M.; Waller, F.; Scholz, U.; Pons-Kühnemann, J.; Sonnewald, S.; Sonnewald, U.; et al. Manipulation of plant innate immunity and gibberellin as factor of compatibility in the mutualistic association of barley roots with Piriformospora indica. Plant J. 2009. [CrossRef]

83. Lee, Y.C.; Johnson, J.M.; Chien, C.T.; Sun, C.; Cai, D.; Lou, B.; Oelmüller, R.; Yeh, K.W. Growth promotion of Chinese cabbage and Arabidopsis by Piriformospora indica is not stimulated by mycelium-synthesized auxin. Mol. Plant-Microbe Interact. 2011. [CrossRef] [PubMed]

84. Franken, P. The plant strengthening root endophyte Piriformospora indica: Potential application and the biology behind. Appl. Microbiol. Biotechnol. 2012, 96, 1455-1464. [CrossRef] [PubMed]

85. Vadassery, J.; Ranf, S.; Drzewiecki, C.; Mithöfer, A.; Mazars, C.; Scheel, D.; Lee, J.; Oelmüller, R. A cell wall extract from the endophytic fungus Piriformospora indica promotes growth of Arabidopsis seedlings and induces intracellular calcium elevation in roots. Plant J. 2009. [CrossRef] [PubMed]

86. Camehl, I.; Drzewiecki, C.; Vadassery, J.; Shahollari, B.; Sherameti, I.; Forzani, C.; Munnik, T.; Hirt, H.; Oelmüller, R. The OXI1 kinase pathway mediates piriformospora indica-induced growth promotion in arabidopsis. PLoS Pathog. 2011, 7, e1002051. [CrossRef] [PubMed]

87. White, J.F.; Torres, M.S. Is plant endophyte-mediated defensive mutualism the result of oxidative stress protection? Physiol. Plant. 2010, 138, 440-446. [CrossRef]

88. Hamilton, C.E.; Gundel, P.E.; Helander, M.; Saikkonen, K. Endophytic mediation of reactive oxygen species and antioxidant activity in plants: A review. Fungal Divers. 2012, 54, 1-10. [CrossRef]

89. Baltruschat, H.; Fodor, J.; Harrach, B.D.; Niemczyk, E.; Barna, B.; Gullner, G.; Janeczko, A.; Kogel, K.H.; Schäfer, P.; Schwarczinger, I.; et al. Salt tolerance of barley induced by the root endophyte Piriformospora indica is associated with a strong increase in antioxidants. New Phytol. 2008. [CrossRef]

90. Kumar, M.; Yadav, V.; Tuteja, N.; Johri, A.K. Antioxidant enzyme activities in maize plants colonized with Piriformospora indica. Microbiology 2009, 155, 780-790. [CrossRef]

91. Sun, C.; Johnson, J.M.; Cai, D.; Sherameti, I.; Oelmüller, R.; Lou, B. Piriformospora indica confers drought tolerance in Chinese cabbage leaves by stimulating antioxidant enzymes, the expression of drought-related genes and the plastid-localized CAS protein. J. Plant Physiol. 2010. [CrossRef]

92. Xu, L.; Wang, A.; Wang, J.; Wei, Q.; Zhang, W. Piriformospora indica confers drought tolerance on Zea mays L. through enhancement of antioxidant activity and expression of drought-related genes. Crop J. 2017, 5 , 251-258. [CrossRef] 